\title{
SATELLITE-BASED CHINA'S PM2.5 POLLUTION AND ASSOCIATED PREMATURE MORTALITY MEASUREMENT OVER PAST TWO DECADES
}

\author{
Shenxin $\mathrm{Li}^{1}$, Bin Zou ${ }^{1 *}$, Jiewen You ${ }^{1}$, Xin Fang ${ }^{1}$, Xiuge Zhao ${ }^{2}$, Xueheng Yao ${ }^{3}$ \\ ${ }^{1}$ School of Geosciences and Info-Physics, Central South University, Changsha, Hunan, China - shenxin823@csu.edu.cn, \\ 210010@csu.edu.cn,175011025@csu.edu.cn,xinfang@csu.edu.cn \\ ${ }^{2}$ State Key Laboratory of Environmental Criteria and Risk Assessment, Chinese Research Academy of Environmental Sciences, \\ Beijing, China - hkyzhaoxg@163.com \\ ${ }^{3}$ Information Centre of Changsha Municipal Bureau of Land and Resources - rocket1028@126.com
}

Commission III, WG III/8

KEY WORDS: $\mathrm{PM}_{2.5}$ pollution, spatial-temporal variation, premature mortality, long-term trend

\begin{abstract}
:
Assessments of the burden of air pollution at the national scale over long-term of time in China would help government managers control historic health impacts of air pollution and institute measures to avoid these risks in future. We took a new $0.01^{\circ}$ $\times 0.01^{\circ}$ satellite-based $\mathrm{PM}_{2.5}$ dataset to analyse spatial and temporal trends of $\mathrm{PM}_{2.5}$ associated premature mortality in China from 1998 to 2017. Results showed that national PM$_{2.5}$ related deaths from STK, IHD, COPD, LC and ALRI increased from approximately 0.89 million cases in 1998 to the peak of 1.34 million in 2014 and steady declined to 1.17 million cases in 2017 . The health burden exhibited strong spatial variations, with high attributable deaths concentrated in regions such as Shandong, Hebei, Henan, Beijing, Guangdong, et al. Changing trends varied from different provinces such as Shandong increased mostly, and Sichuan showed a significant decreasing trend. Meanwhile, the results also showed that the expand directions of premature mortality was similar to that of population and the changing of absolute number of premature mortality more depended on the growth of $\mathrm{PM}_{2.5}$ concentration. The findings recommend that government should make better policies to the health risk controlling which take population and pollution into consideration than only focus on pollution concentration.
\end{abstract}

\section{INTRODUCTION}

Rapid growth of urbanization and industrialization led air pollution become a serious environmental issue in China. Studies reported that ambient particulate matter was the sixth-ranking mortality risk factor in 2016 (GBD, 2016) of the world and it was the 4th among all the risk factor for premature mortality in China (Yang et al., 2013). Numerous epidemiological cohort studies have demonstrated that long term exposure to high level $\mathrm{PM}_{2.5}$ concentration was associated with premature mortality from endpoints such as stroke (STK), ischemic heart disease (IHD), chronic obstructive pulmonary disease (COPD), lung cancer (LC) and acute lower respiratory infection (ALRI) (Brauer et al., 2012).

Some studies have tried to evaluate health impacts due to ambient $\mathrm{PM}_{2.5}$ for China in recent years. Some of them not considered the national scale (Cao et al., 2012; Yi et al., 2015; Fang et al., 2016) and fine resolution (Liu et al., 2016; Cohen et al., 2017), others have improved these negatives on spatial scales but not take the long-term variations (Lelieveld et al., 2015; Lim et al., 2012; Feng et al., 2017; Wang et al., 2018) into consideration. Recently, there were two studies (Liu et al., 2016, Xie et al., 2016, have reported national premature deaths contributed by $\mathrm{PM}_{2.5}$ pollution during 2004-2012 and 20002010 respectively, but different spatial resolutions and baseline mortality led the results of these two studies incomparable, furthermore, it is hard to integrate a long-term dataset of premature deaths in a fine resolution in China based on present studies.

To address this need, we used a new $0.01^{\circ} \times 0.01^{\circ}$ satellite-based $\mathrm{PM}_{2.5}$ data dataset in conjunction with fine scale population data to develop novel estimates of $\mathrm{PM}_{2.5}$ related premature mortality in China from 1998 to 2017 at national scale. The specific objectives were (1) to reveal the spatiotemporal characteristics of $\mathrm{PM}_{2.5}$ concentrations in China through 1998 to 2017, (2) estimate the health effects of $\mathrm{PM}_{2.5}$ concentration in China and (3) explore the relationship of change tendency between concentration, population and premature mortality .The results of this study will aid in understanding the characteristics of the long-term trends of $\mathrm{PM}_{2.5}$ in China and their health effects during periods of past 20-years, and they will also have implications in designing effective strategies to mitigate health damage caused by air pollution in China and developing countries elsewhere.

\section{DATA AND METHODS}

\subsection{Data collection and preparation}

2.1.1 PM2.5 concentration data: We used global $\mathrm{PM}_{2.5}$ concentrations for 1998-2017 estimated using remote sensing data from the Atmospheric Composition Analysis Group to analyse the spatiotemporal dynamics of $\mathrm{PM}_{2.5}$ concentration in China. The datasets was estimated by combining Aerosol Optical Depth (AOD) retrievals from the NASA MODIS (MODerate resolution Imaging Spectroradiometer), MISR (Multi-angle Imaging SpectroRadiometer) and SeaWIFS (Seaviewing Wide Field-of-view Sensor) instruments and MODIS MAIAC (Multi-Angle Implementation of Atmospheric Correction) surface reflectance dataset with the GEOS-Chem chemical transport model and subsequent calibration to global ground-based observations of $\mathrm{PM}_{2.5}$ using Geographically Weighted Regression (GWR) (van Donkelaar et al., 2016). The remote sensing data are based on the statistical method of using average as the annual average with a resolution of $0.01^{\circ} \times 0.01^{\circ}$. To match the resolution of population data, the $\mathrm{PM}_{2.5}$ concentration data was resampled to $1 \mathrm{~km} \times 1 \mathrm{~km}$ resolution.

2.1.2 Population data: A series of data need to be collected to estimate the spatial distribution of population for the years 1998-2017. Using the provincial growth rate projection method. It included the $1 \mathrm{~km} \times 1 \mathrm{~km}$ grid population data of China in 2010 from the Chinese Academy of Sciences Resource and Environment Science Data Centre (http://www.resdc.cn), the data from a series of China Statistic Yearbooks and Annual Statistical Bulletin (http://www.stats.gov.cn/tjsj/tjgb/ndtjgb/), and the provincial age characteristic data from the website of 
the National Bureau of Statistics of the People's Republic of China (http://www.stats.gov.cn/tjsj/pcsj/rkpc/6rp/indexch.htm).

2.1.3 Mortality data and death rate of disease: The provincial death rate of disease was collected from the reference written by Zhou et al. The data included the age-standardized death rate of each province for men and women in 2013, this study firstly estimate the provincial death rate of disease in 2013 according to the population proportion of men and women, then calculated the death rate of each disease in each year based on the temporal relationship of mortality during the study period. The yearly provincial population proportion of men and women and the mortality data was collected from China Statistic Yearbooks and Annual Statistical Bulletin (http://www.stats.gov.cn/tjsj/tjgb/ndtjgb/).

\subsection{Methods}

2.2.1 IER model: Premature mortalities attribute to longterm exposure to $\mathrm{PM}_{2.5}$ were calculated based on the equation with exposure factors weighting. Five leading endpoints were considered, including ischemic heart disease (IHD), lung cancer (LC), stroke (STK, including ischemic stroke and haemorrhagic stroke), chronic obstructive pulmonary disease (COPD) and acute lower respiratory infection (ALRI) of child aged $<5$ years.

The exposure-response function is used to quantitatively evaluate the change in the death rate caused by a unit increase in a pollutant's concentration level. The Integrated Exposure Response (IER) model developed as part of the GBD study seems to be the most suitable choice for the estimates of mortality burdens attributable to $\mathrm{PM}_{2.5}$ in China. Even compared with the RRs estimated based on

$$
E D_{i, j, t}=\left(1-\frac{1}{R R_{i, j, t}}\right) \times I_{i, j, t} \times P_{t, j, t}=A F_{i, j, t} \times I_{i, j, t} \times P_{i, j, t}
$$

Where

$E D_{i, j,}=$ the excess deaths caused by air pollution for stroke, IHD or LC;

$A F_{i, j, t}=$ the attributable fraction (AF), defined as the fraction of the disease burden attributable to $\mathrm{PM}_{2.5}$;

$I_{i, j, l}=$ the annual all-age incidence rate of the mortality end point, obtained from China Health Statistical Yearbook () compiled by the Ministry of Health of China according to ICD10 codes (NHFPCC, );

$P_{i, j, t}=$ the permanent all-age population aggregated from population density map at $1 \mathrm{~km} \times 1 \mathrm{~km}$ resolution provided by Chinese Academy of Science;

$R R_{, j, t}=$ the relative risk of premature mortality due to $\mathrm{PM}_{2.5}$ obtained from the integrated exposure response model and $i, j$ and $t$ are the grid, the prefecture and the year, respectively.

2.2.2 Standard Deviation Ellipse Analysis: The standard deviation ellipse represents elements in the main distribution area. The calculated major and minor axes of the ellipse indicate the direction and range of the data distribution. Thus, the calculated multiyear SDE can reflect clear trends in the directionality of the elements over time. The median centre identifies the location that minimizes the overall Euclidean distance to the features in a dataset; therefore, it can express the centre of the entire dataset. By comparing the interannual changes in the SDE and median centre of the time series, it was possible to determine the overall characteristics of premature mortality and the corresponding $\mathrm{PM}_{2.5}$ concentrations and populations in 1998 and 2017 were quantified to trace their changes over the past 20 years.

\section{RESULTS}

\subsection{Spatiotemporal characteristics of $\mathbf{P M}_{2.5}$ pollution during past 20 years}

3.1.1 Temporal characteristics of $\mathbf{P M}_{2.5}$ pollution during past 20 years: The variation of annual average $\mathrm{PM}_{2.5}$ concentration shows in figure 1 . The average value of national $\mathrm{PM}_{2.5}$ concentration varied from $22.33 \mu \mathrm{g} / \mathrm{m}^{3}$ (in 2000) to 31.26 $\mu \mathrm{g} / \mathrm{m}^{3}$ (in 2015) and the average value during 1998-2017 is $28.13 \mu \mathrm{g} / \mathrm{m}^{3}$. There was a decrease from $1998\left(23.90 \mu \mathrm{g} / \mathrm{m}^{3}\right)$ to $2000\left(22.33 \mu \mathrm{g} / \mathrm{m}^{3}\right)$ and sharply increase from $2000(22.33$ $\left.\mu \mathrm{g} / \mathrm{m}^{3}\right)$ to $2007\left(31.16 \mu \mathrm{g} / \mathrm{m}^{3}\right)$. During 2007 and 2010, the concentration of annual average stayed in a stable interval of $29.75 \mu \mathrm{g} / \mathrm{m}^{3}$ and $31.16 \mu \mathrm{g} / \mathrm{m}^{3}$. There was a significant decreasing from $2010\left(31.12 \mu \mathrm{g} / \mathrm{m}^{3}\right)$ to $2012\left(27.31 \mu \mathrm{g} / \mathrm{m}^{3}\right)$ and increased to $31.23 \mu \mathrm{g} / \mathrm{m} 3$ in 2013 , it decreased to $29.22 \mu \mathrm{g} / \mathrm{m}^{3}$ in 2014 and then raise to $31.26 \mu \mathrm{g} / \mathrm{m}^{3}$ in 2015 as the peak value during the past 20 years. After 2015, the annual $\mathrm{PM}_{2.5}$ concentration declined for two consecutive years to the value of $28 \mu \mathrm{g} / \mathrm{m}^{3}$ and $29.22 \mu \mathrm{g} / \mathrm{m}^{3}$ in 2016 and 2017.

Fig.1. also shows the rates of area exceeded different level of air quality standard and the corresponding rate value of population. The three level of concentration limitation are according to the three different limitation of air quality standard: Grade I of National Ambient Air Quality Standard in China (CNAAQS) (annual concentration limit is $15 \mu \mathrm{g} / \mathrm{m}^{3}$ ), Grade II of National Ambient Air Quality Standard in China (CNAAQS) (annual concentration limit is $35 \mu \mathrm{g} / \mathrm{m}^{3}$ ), and the Air Quality Standard of WHO $\left(10 \mu \mathrm{g} / \mathrm{m}^{3}\right)$. The rates of area exceeded concentration limitation of $10 \mu \mathrm{g} / \mathrm{m}^{3}, 15 \mu \mathrm{g} / \mathrm{m}^{3}$ and $35 \mu \mathrm{g} / \mathrm{m}^{3}$ varied from $72 \%$ to $85 \%, 58 \%$ to $75 \%$, and $19 \%$ to $38 \%$, respectively. Compared to the rates of population of exceeding concentration limitation of the three level which varied from $98 \%$ to $99 \%, 92 \%$ to $98 \%$, and $39 \%$ to $79 \%$. Since 2013 , the year of drastic measures of air pollution controlling was taken by Chinese Government, annual-average concentration was declined in a total trend from $31 \mu \mathrm{g} / \mathrm{m}^{3}$ to $27 \mu \mathrm{g} / \mathrm{m}^{3}$ until 2017. With the decreasing of concentration, the rate of area exceeding $35 \mu \mathrm{g} / \mathrm{m}^{3}$ dropped from $35 \%$ to $25 \%$ and the rate of population exceeding 35 $\mu \mathrm{g} / \mathrm{m}^{3}$ from $72 \%$ down to $55 \%$, the variation reveals that strict measures have effective results on air pollution controlling specially on the heavily polluted areas and high-density population areas. The little changes of the rate of area exceeding $10 \mu \mathrm{g} / \mathrm{m}^{3}, 15 \mu \mathrm{g} / \mathrm{m}^{3}$ and the rate of population exceeding 10 $\mu \mathrm{g} / \mathrm{m}^{3}, 15 \mu \mathrm{g} / \mathrm{m}^{3}$ indicated that it is hard to reduce the concentration of areas with relatively good air quality.

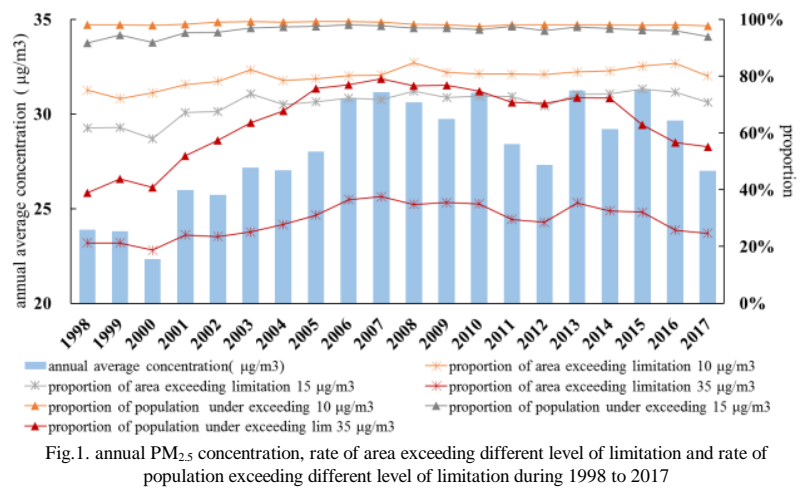


3.1.2 Spatial characteristics of $\mathbf{P M}_{2.5}$ pollution during past 20 years: Figure 2 shows significant spatial characteristics of $\mathrm{PM}_{2.5}$ pollution throughout the whole country during the past 20 years. The North China Plain was the centre of high $\mathrm{PM}_{2.5}$ concentration area, it concluded BTH region, Shandong city cluster, north and central Henan, north Anhui and north Jiangsu. The North China Plain has always been one of the most concentrated areas in China's population and the most intensive social and economic activities. Concentration of the Fen Wei plains and Sichuan basin were also high, large density of population and diffusion of adverse weather conditions led these areas kept high concentration of pollution.

The lightest polluted area of $\mathrm{PM}_{2.5}$ is northeast and southwest China and southeast coastal area. These two areas are mountainous and many trees, with sparse population density and poor economic development. The low emissions of human pollutants and strong resistance to natural environment make the air quality of the two regions far ahead of the whole country.

Fig.2. also shows the spatial variation of total $\mathrm{PM}_{2.5}$ concentration. Northeast China Pain and North China Plain were the areas $\mathrm{PM}_{2.5}$ concentration increased mostly. Coal was the main energy consumption in the Northeast Plain during the past 20-years, the increasing accounting of the total energy consumption (Jilin Statistical Yearbook, 2016, Liaoning Statistical Yearbook, 2017, Heilongiiang Statistical Yearbook 2017), resulting heavy air pollution in this area. Industry and vehicle emissions were main sources of air pollution in North China Plain. High density of population and rapid increasing rate of population led to explosive growth of motor vehicles in this area, e.g.: Beijing from 1.16 million in 1998 to 5.59 million in 2014 (Beijing Statistical Yearbook, 1999 and 2015), Tianjin from 0.4 million in 1998 to 2.82 million in 2016 (Tianjin Statistical Yearbook, 1999 and 2017).

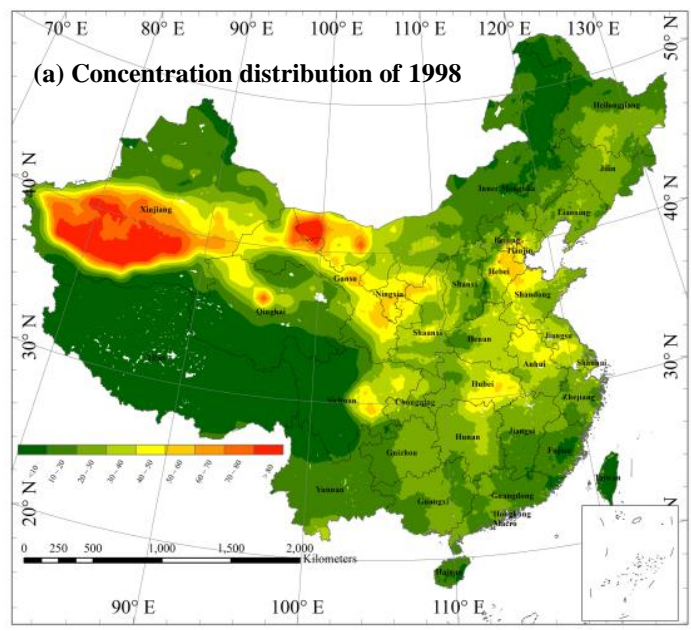

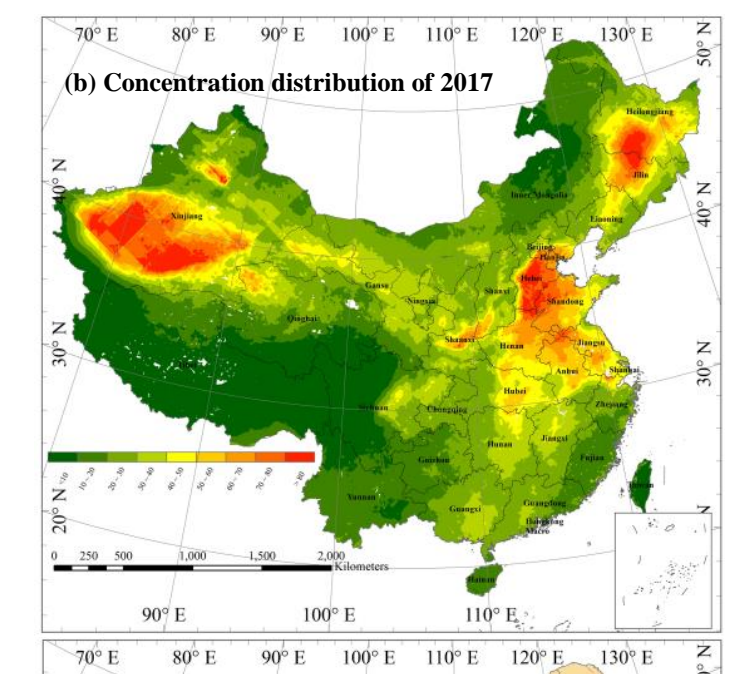

(c) variation between 1998 and 2017

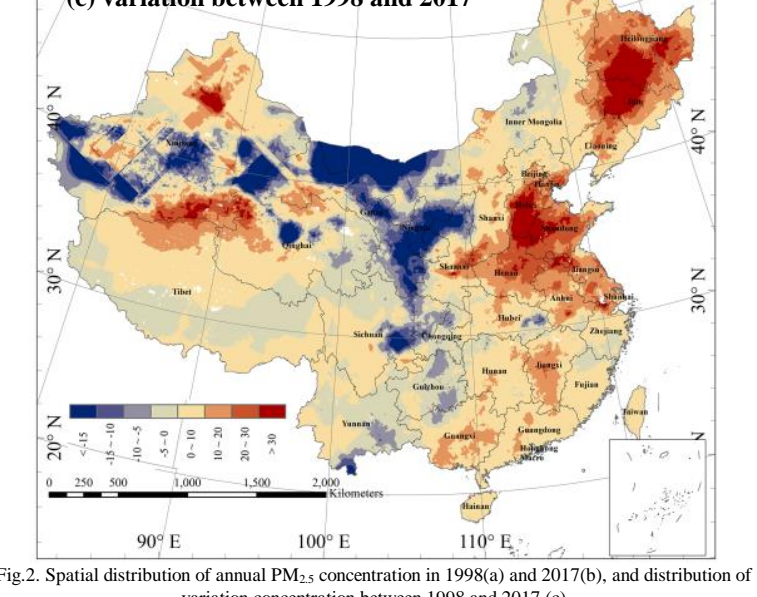

variation concentration between 1998 and 2017 (c)

\subsection{Estimation of $\mathbf{P M}_{2.5}$ associated premature mortality}

3.2.1 Total premature mortality varied with time: Figure 3 shows the total premature mortality varied with time during 1998-2017. In past 20-years, the estimated total average annual premature mortality due to $\mathrm{PM}_{2.5}$ exposure in China reached $1,125,779$. The five diseases contributed differently to the total annual average. The estimates of annual premature mortality from STK, IHD, COPD, LC, and ALRI attributable to ambient $\mathrm{PM}_{2.5}$ numbered 604,271, 303,327, 124,449, 90,479, and 3,225, respectively.

Fig.3. presents the five diseases deaths, total premature mortality and their change rates of each year during 1998 to 2017. Overall, $\mathrm{PM}_{2.5}$ induced premature mortality in China showed an increasing trend from 1998 to 2017. The overall annual $\mathrm{PM}_{2.5}$ contributed premature mortality varied from 885,265 (in 1998) to $1,340,920$ (in 2014). The premature mortality increased dramatically from 1998 to 2003 with a rising rate of $18.56 \%$, then showed a small decline in 2014 and stably raise during 2005 to 2008 . There were continuous declines from 2009 and sharply increasing from 2012 then got the peak value of total premature mortality in 2014 with the number of $1,340,920$. There was a significant decline since 2015 and the total premature mortality dropped to $1,167,470$ in 2017.

3.2.2 Five diseases deaths varied with time: The five diseases showed different changing characteristics during the 
past 20-years. (Fig3) The number of ALRI deaths changed most, following was LC deaths and COPD deaths, STK deaths was the fourth and the change of IHD deaths is the smallest. The number of ALRI deaths was increasing from 2,220 to 3,852 with the variation of $42.36 \%$ during 1998 to 1997 , and decreased during 2008 to 2012, it was increased in 2013 and then declined until 2017. The number of LC deaths and COPD deaths were with similar tendency of variation that increased from 1998 to 2007 and small decline during 2008 to 2012, the got the peak value in 2013 and declined from 2014 to 2017 .

The change tendency of STK deaths and IHD deaths were similar with the peak value in 2014 . Therefore, the percentage contributions of five diseases deaths were quantified during the long-term changes over the entire of China (Fig.3.). In terms of their relative contributions, STK, IHD, COPD, LC, and ALRI accounted for $53.68 \%, 26.94 \%, 11.05 \%, 8.04 \%$ and $0.29 \%$, respectively, of total premature mortality in China. Because of the variations in the trends of the five diseases and their absolute amounts, their relative contributions to total premature mortality also varied during the 20 -years period. The changes in the proportions of the contributions of the diseases to total premature mortality showed that LC and ALRI changed little annually with the proportion values varying from $7.32 \%$ to $8.32 \%$ and $0.25 \%$ to $0.32 \%$. Both STK (varied from $52.74 \%$ to $54.58 \%$ ) and COPD (varied from $10.54 \%$ to $11.72 \%$ ) increased their contributions from 1998 to 2017 with max increases in their proportions, corresponding to a decrease in the percentage contribution of IHD (varied from $29.07 \%$ to $26.97 \%$ ) to total premature mortalities.

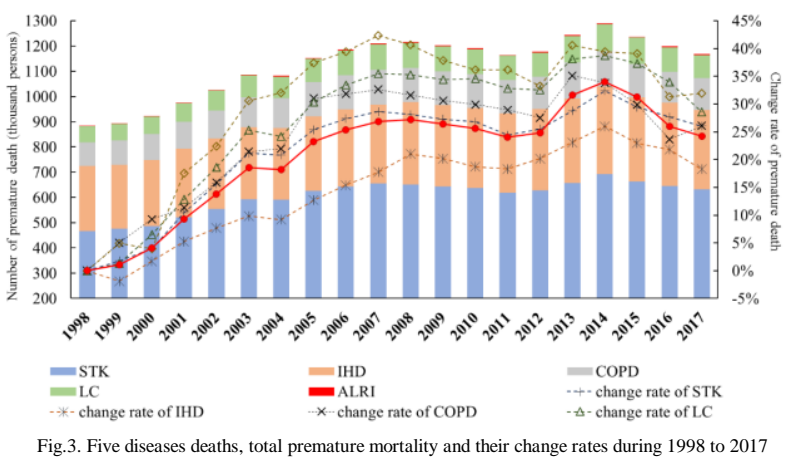

3.2.3 Spatial distribution of premature mortality: Figure 4 presents the spatial distribution of estimated annual $\mathrm{PM}_{2.5}$ related premature mortality linked to COPD, IHD, STK, LC and ALRI in China during 1998-2017. In general, premature mortality showed obvious spatial patterns and strong variations across the entire study area from 1998 to 2017. High levels of premature mortality were widespread in Beijing, Tianjin, Shanghai, southern Hebei, north-eastern Henan, western Shandong, southern Jiangsu, central Shaanxi, Wuhan urban agglomeration, Chengdu-Chongqing city cluster and southern Guangdong. These areas showed the highest numbers of estimated premature mortality because of high $\mathrm{PM}_{2.5}$ concentrations and high population densities. Other regions with high values of premature mortality were mainly in provincial capital cities of central and eastern China. Corresponding to the dense population centres of urban areas throughout the study period. Cities of Harbin, Shenyang, Shijiazhuang, Jinan, Taiyuan, Xingtai, Wuhan, Hefei and Chongqing were with high premature mortality of per square kilometre (exceeded 15 persons) in 1998 and it was expanded to Changchun, Beijing, Tianjin, Baoding, Handan, Qingdao and Zhengzhou in 2017.
Meanwhile, the proportion of areas per square kilometre deaths over 6 persons was growth from $3.23 \%$ to $5.15 \%$ during 1998 to 2017.The proportion of premature mortality of per square kilometre between 4 to 6 persons and that of 2 to 4 persons also showed rising trend with the value from $1.72 \%$ to 2.83 and $4.49 \%$ to $8.83 \%$. In the contrary, the area of premature mortality account for $80.46 \%$ in 1999 and for $67.97 \%$ in 2016. The provincial absolute number of deaths of premature mortality varied significantly. The largest increase of absolute number of deaths of premature mortality occurred in Shandong (from 94,797 to 155,052 , increased 60,256) and Henan (from 104,666 to 155,052 , increased 47,431 ), followed by Hebei (from 77,528 to 113,381 , increased 35,852 ), Heilongjiang (from 30,599 to 64,063, increased 33,464) and Guangdong (from 48,605 to 77,418 , increased 28,813). Heilongjiang, Beijing, Hainan, Jilin and Shandong were also the top five provinces with high increasing rate of premature mortality and the value were $109.36 \%, 89.53 \%, 85.24 \%, 65.29 \%, 63.56 \%$, respectively. Contrary to the increasing provinces, Sichuan, Guizhou, Yunnan, Gansu, Chongqing, and Gansu showed significant decreasing trend with the declined death numbers were 11,414, $8,692,5,152,4,489$ and 4,345 respectively. Meanwhile, Tibet (from 57 to 23 , declined $58.87 \%$ ) was the province which change rate of premature mortality dropped mostly, following were Guizhou (from 33,139 to 24,446, declined 26.23\%), Yunnan (from 22,407 to 17,256, declined 22.99\%), Gansu (from 28,680 to 24,336, declined 15.15\%), Chongqing (from 31,795 to 27,307 , declined $14.12 \%$ ), and Sichuan (from 81,426 to 70,012 , declined $14.02 \%$ ).
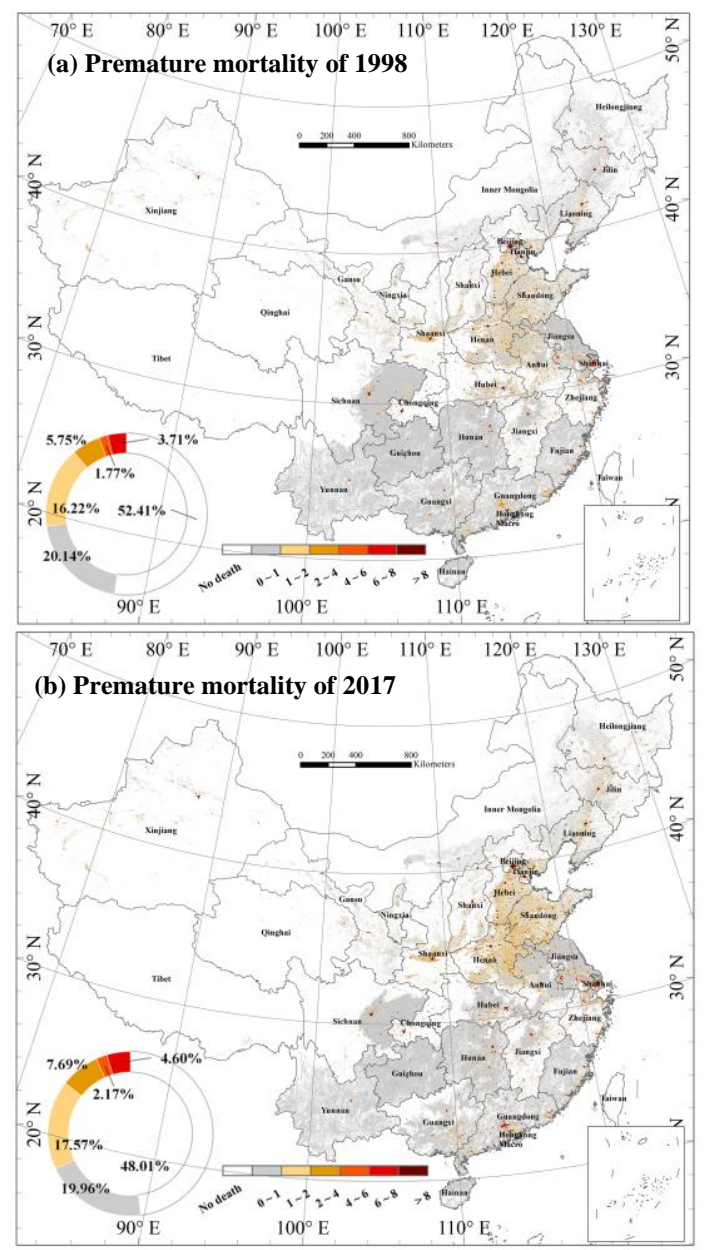

Fig.4. Spatial distribution of premature deaths in 1998 (a) and 2017 (b)

3.2.4 Provincial changes of absolute number and death 
rate of premature mortality: Overall, the number of premature mortality did not always increase in all areas within an individual province. It generally occurred where both $\mathrm{PM}_{2.5}$ concentration and population density were high or in areas with very high population densities. Furthermore, these regions were usually the areas with the highest increments in absolute premature mortality between 1998 and 2017. Conversely, the number of premature mortality in areas with reduced $\mathrm{PM}_{2.5}$ concentrations or low population densities in China changed little between 1998 and 2017.

The provincial absolute number of deaths of premature mortality varied significantly. The largest increase of absolute number of deaths of premature mortality occurred in Shandong (from 94,797 to 155,052, increased 60,256) and Henan (from 104,666 to 155,052 , increased 47,431), followed by Hebei (from 77,528 to 113,381, increased 35,852), Heilongjiang (from 30,599 to 64,063 , increased 33,464) and Guangdong (from 48,605 to 77,418 , increased 28,813). Heilongjiang, Beijing, Hainan, Jilin and Shandong were also the top five provinces with high increasing rate of premature mortality and the value were $109.36 \%, 89.53 \%, 85.24 \%, 65.29 \%, 63.56 \%$, respectively. Contrary to the increasing provinces, Sichuan, Guizhou, Yunnan, Gansu, Chongqing, and Gansu showed significant decreasing trend with the declined death numbers were 11,414 , $8,692,5,152,4,489$ and 4,345 respectively. Meanwhile, Tibet (from 57 to 23 , declined $58.87 \%$ ) was the province which change rate of premature mortality dropped mostly, following were Guizhou (from 33,139 to 24,446, declined 26.23\%), Yunnan (from 22,407 to 17,256, declined 22.99\%), Gansu (from 28,680 to 24,336, declined 15.15\%), Chongqing (from 31,795 to 27,307 , declined $14.12 \%$ ), and Sichuan (from 81,426 to 70,012 , declined $14.02 \%$ ).

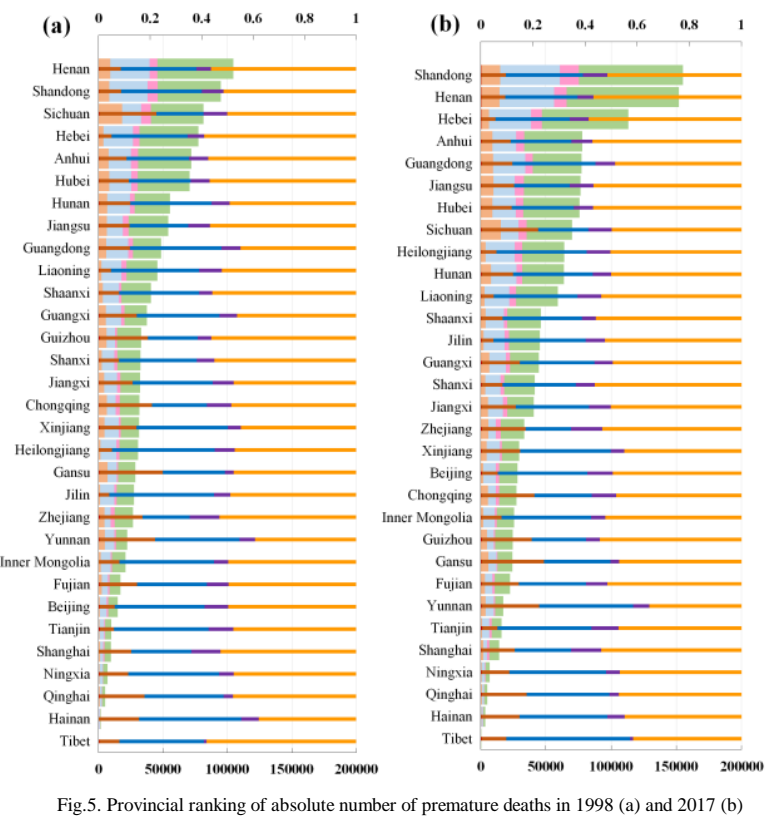

\subsection{Changing tendency of premature mortality}

Figure 6 shows the overall changes in the spatial pattern of $\mathrm{PM}_{2.5}$ concentration, population distribution and premature mortality across China between 1998 and 2017 were evaluated using median centre and SDE analysis, which revealed the central location and elements distributed within the main region The results showed that the median centre of concentration in each year located in the area between $104^{\circ} \mathrm{E} \sim 110^{\circ} \mathrm{E}$ and $34^{\circ} \mathrm{N}$ $\sim 38^{\circ} \mathrm{N}$ (mainly in south Gansu, Shaanxi and Shanxi) and moved from northwest to southeast between 1998 and 2007 and from southeast to northwest during 2008 and 2017. Compared with the median centre of premature mortality of $\mathrm{PM}_{2.5}$ pollution, the median centre point varied between $118^{\circ} \mathrm{E}$ $120^{\circ} \mathrm{E}$ and $33^{\circ} \mathrm{N} \sim 34^{\circ} \mathrm{N}$ (mainly in Henan province) and the median centre of population distribution varied located in areas of $116^{\circ} \mathrm{E} \sim 117^{\circ} \mathrm{E}$ and $32^{\circ} \mathrm{N} \sim 33^{\circ} \mathrm{N}$.

The SDE showed that the main distribution of $\mathrm{PM}_{2.5}$ concentration was aligned in the northwest-southeast direction and that it increased gradually in this direction. The major and minor axes of the ellipse declined from 1707 to $1770 \mathrm{~km}$ and from 937 to $1039 \mathrm{~km}$, respectively. The increasing of the major axes of the ellipses illustrated the spatial aggregation tendency and the minor axes showed the of $\mathrm{PM}_{2.5}$ concentration from 1998 and 2017. The major and minor axes of premature ellipse decreased in length from 977 to $1023 \mathrm{~km}$ and from 862 to 791 $\mathrm{km}$, respectively. The different lengths of the major and minor axes of $\mathrm{PM}_{2.5}$ population, and premature mortality demonstrated different distributional patterns of these three elements across China. The ratio between the major and minor axes of the ellipses calculated by premature mortality presented an increasing tendency between 1998 and 2017, indicating that the directional trend became increasingly evident, which displayed patterns consistent with $\mathrm{PM}_{2.5}$ concentration and population. By 2017, the ellipse of premature mortality moved northwest relative to 1998 . The rotation of $\mathrm{PM}_{2.5}$ concentration varied from $107.10^{\circ}$ to $99.67^{\circ}$ and that of premature mortality varied from $43.0^{\circ}$ to $27.46^{\circ}$.

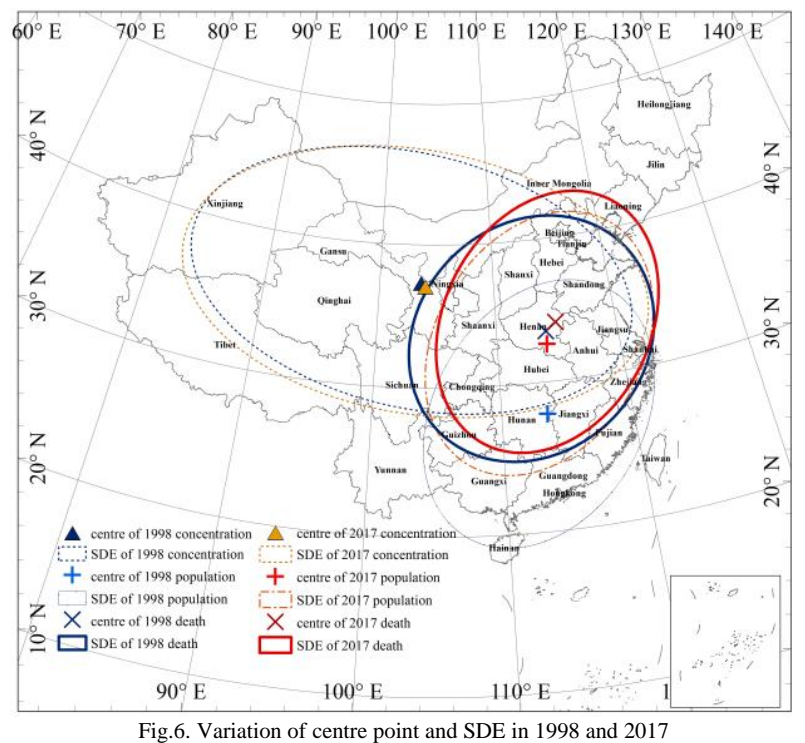

\section{DISCUSSION AND CONCLUSIONS}

We firstly compared our outcomes with other recent studies in China and worldwide in different years, including the studies that adopted the IER model (Lim et al., 2012, Lelieveld et al., 2015, Liu et al., 2016a, Liu et al., 2016b, Xie et al., 2016, Wang et al., 2018), and found that our estimate of national premature mortality attributed to $\mathrm{PM}_{2.5}$ in each year was closed to the results of the following studies: Xie et al. (in 2016, estimated 0.88 million in 2000 and 1.25 million in 2010 compared with 0.92 million and 1.19 million in this study), Wang et al. (in 2018, estimated 1.21 million in 2010 compared with 1.19 million in this study), Liu et al. (in ). 1.27 million Wang et al. M. Liu et al. (2016b) also used the IER models and a satellite-derived $\mathrm{PM}_{2.5}$ dataset at 10 resolution, and all-age population maps at $1 \mathrm{~km}$ resolution in 2010 ; the endpoint ALRI and COPD death was not included in their study. Xie et al. (2016) explored the long-term trend and spatial pattern of $\mathrm{PM}_{2.5}$ induced premature mortality in China between 2000 and 2010 based on 
the same $1 \mathrm{~km}$ resolution population density, satellite retrieved $\mathrm{PM}_{2.5}$ concentrations and provincial health data. Our results were lower than the 1.36 million by Lelieveld et al. (2015), the 1.37 million by J. Liu et al (2016a). These differences in $\mathrm{PM}_{2.5}$ related mortality may be due to the use of different data sources for $\mathrm{PM}_{2.5}$ exposure data, the modelling scale, the population data, and the annual incidence rate of mortality for the five diseases.

Secondly, we compared the proportion of five diseases in this study with other studies. Among the $\mathrm{PM}_{2.5}$ related premature mortality, the contribution of STK is the largest $(52.90 \%)$, followed by IHD $(30.77 \%)$, COPD and LC accounted for $9.40 \%$ and $6.62 \%$, respectively, and the proportion of ALRI in children was the lowest at around $0.32 \%$ (Fig, for each of the previous studies). IHD and STK account for $>80 \%$ of combined $\mathrm{PM}_{2.5}$ attributable mortality for all five causes, which is higher than the $\sim 70 \%$ of the previous global concentration mortality relationships (Apte et al., 2015) and the 72\% from GBD 2010.

This study estimate dataset of yearly annual $\mathrm{PM}_{2.5}$ associated premature mortality based on the $0.01^{\circ} \times 0.01^{\circ}$ high-resolution over the past two decades. The results show that $\mathrm{PM}_{2.5}$-induced premature mortality increased from 0.89 million in 1998 to the peak of 1.34 million in 2014 and steady declined to 1.17 million in 2017. Among the five diseases, STK and IHD were the two largest contributors, accounting for over $80 \%$ of the total premature mortality in China. Among all provinces, Henan contributed the largest premature mortality across the study area with 137,166 and accounting for $12.1 \%$. The spatial pattern showed that high levels of premature mortality were widespread in Beijing, Tianjin, Shanghai, southern Hebei, north-eastern Henan, western Shandong, southern Jiangsu, central Shaanxi, Wuhan urban agglomeration, Chengdu-Chongqing city cluster and southern Guangdong. These areas showed the highest numbers of estimated premature mortality because of high $\mathrm{PM}_{2.5}$ concentrations and high population densities. Other regions with high values of premature mortality were mainly in provincial capital cities of central and eastern China. The results also show the expand directions of premature mortality were similar to that of population and the changing of absolute number of premature mortality more depended on the growth of $\mathrm{PM}_{2.5}$ concentration. Long-term premature mortality of $\mathrm{PM}_{2.5}$ concentration was affected by urbanization during past 20 -years. The comparation of the results showed our estimated of long-term $\mathrm{PM}_{2.5}$ contributed premature mortality were closed to most of previous studies in each year and the dataset of yearly annual $\mathrm{PM}_{2.5}$ associated premature deaths over the past two decades is dependable. The result also shows that it is a big challenge for our government and society to make better policies to balance the relationship between economic development and human health impact caused by environmental pollution, and government should make better policies to the health risk controlling which take population and pollution into consideration than only focus on pollution concentration.

\section{ACKNOWLEDGEMENTS (OPTIONAL)}

This work was supported by the National Key Research and Development Program (2016YFC206205 and 2016YFC206201), the National Science Foundation of China (No. 41871317).

\section{REFERENCES}

Arnold C, 2014. Disease Burdens Associated with $\mathrm{PM}_{2.5}$ Exposure: How a New Model Provided Global Estimates. Environmental Health Perspectives, 122(4): A111.

Boys, B. L., Martin, R. V., Donkelaar, A. V., Macdonell, R. J., Hsu, N. C., \& Cooper, M. J., et al, 2014. Fifteen-year global time series of satellite-derived fine particulate matter. Environmental Science \& Technology, 48(19), 11109.

Burnett R T, Iii C A P, Ezzati M, et al, 2014. An Integrated Risk Function for Estimating the Global Burden of Disease
Attributable to Ambient Fine Particulate Matter Exposure. Environmental Health Perspectives, 122(4):397-403.

Brauer M, Amann M, Burnett R T, et al, 2012. Exposure Assessment for Estimation of the Global Burden of Disease Attributable to Outdoor Air Pollution. Environmental Science \& Technology, 46(2):652-660.

Brauer M, Freedman G, Frostad J, et al, 2015. Ambient Air Pollution Exposure Estimation for the Global Burden of Disease 2013. Environmental Science \& Technology, 50(1):79.

Cohen A J, Brauer M, Burnett R, et al, 2017. Estimates and 25year trends of the global burden of disease attributable to ambient air pollution: an analysis of data from the Global Burden of Diseases Study 2015. Lancet, 389(10082):1907-1918.

Chen Y, Ebenstein A, Greenstone M, et al, 2013. Evidence on the impact of sustained exposure to air pollution on life expectancy from China's Huai River policy. Proceedings of the National Academy of Sciences of the United States of America, 110(32):12936-12941.

Chambliss S E, Silva R, West J J, et al, 2014. Estimating source-attributable health impacts of ambient fine particulate matter exposure: global premature mortality from surface transportation emissions in 2005. Environmental Research Letters, 9(10):104009.

Cheng Z, Jiang J, Fajardo O, et al, 2013. Characteristics and health impacts of particulate matter pollution in China (20012011). Atmospheric Environment, 65(3):186-194.

Donkelaar A V, Martin R V, Brauer M, et al, 2010. Global estimates of average ground-level fine particulate matter concentrations from satellite-based aerosol optical depth. Environmental Health Perspectives, 118:847-855.

Donkelaar A V, Martin R V, Brauer M, et al, 2015. Use of Satellite Observations for Long-Term Exposure Assessment of Global Concentrations of Fine Particulate Matter. Environmental Health Perspectives, 123(2):135.

Donkelaar A V, Martin R V, Brauer M, et al, 2016. Global Estimates of Fine Particulate Matter using a Combined Geophysical-Statistical Method with Information from Satellites, Models, and Monitors. Environmental Science \& Technology, 50(7):3762.

Fang X, Zou B, Liu X, et al, 2016. Satellite-based ground $\mathrm{PM}_{2.5}$ estimation using timely structure adaptive modeling. Remote Sensing of Environment, 186: 152-163.

Feng L, Ye B, Feng H, et al, 2017. Spatiotemporal Changes in Fine Particulate Matter Pollution and the Associated Mortality Burden in China between 2015 and 2016. International Journal of Environmental Research \& Public Health, 14(11):1321.

Hou Q, An X, Wang Y, et al, 2012. An assessment of China's PM10-related health economic losses in 2009. Science of the Total Environment, s 435-436:61-65.

Lelieveld J, Evans J S, Fnais M, et al, 2017. The contribution of outdoor air pollution sources to premature mortality on a global scale. Nature, 525(7569):367-371. 
Lim S S, et al, 2012. A comparative risk assessment of burden of disease and injury attributable to 67 risk factors and risk factor clusters in 21 regions, 1990-2010: a systematic analysis for the global burden of disease study 2010. Lancet, 380:22242260 .

Liu M, Huang Y, Ma Z, et al, 2017. Spatial and temporal trends in the mortality burden of air pollution in China: 2004-2012. Environment International, 98:75.

Landrigan P J, Fuller R, Acosta N, et al, 2017. The Lancet Commission on pollution and health. Lancet, 1(8):1050.

Matus K, Nam K M, Selin N E, et al, 2012. Health damages from air pollution in China. Global Environmental Change, 22(1):55-66.

Ma Z, Hu X, Huang L, et al, 2014. Estimating Ground-Level $\mathrm{PM}_{2.5}$ in China Using Satellite Remote Sensing. Environmental Science \& Technology, 48(13):7436.

Ma Z, Hu X, Sayer A M, et al, 2016. Satellite-Based Spatiotemporal Trends in $\mathrm{PM}_{2.5}$ Concentrations: China, 20042013. Environmental Health Perspectives, 124(2):184-192.

Peng J, Chen S, Lv H, et al, 2016. Spatiotemporal patterns of remotely sensed $\mathrm{PM}_{2.5}$, concentration in China from 1999 to 2011. Remote Sensing of Environment, 174:109-121.

Yin P, Brauer M, Cohen A, et al, 2017. Long-term Fine Particulate Matter Exposure and Nonaccidental and Causespecific Mortality in a Large National Cohort of Chinese Men. Environmental Health Perspectives, 125(11).

Yang G, Wang Y, Zeng Y, et al, 2013. Rapid health transition in China, 1990-2010: findings from the Global Burden of Disease Study 2010. Lancet, 381(9882):1987-2015.

Yang X, Huang Y, Dong P, et al, 2009. An Updating System for the Gridded Population Database of China Based on Remote Sensing, GIS and Spatial Database Technologies. Sensors, 9(2):1128-1140.

Shaddick G, Thomas M, Amini H, et al, 2018. Data integration for the assessment of population exposure to ambient air pollution for global burden of disease assessment. Environmental Science \& Technology, 52(16).

Shi Y, Matsunaga T, Yamaguchi Y, et al, 2018. Long-term trends and spatial patterns of $\mathrm{PM}_{2.5}$-induced premature mortality in South and Southeast Asia from 1999 to 2014. Science of the Total Environment, 631:1504-1514.

Shi Y, Matsunaga T, Yamaguchi Y, et al, 2018. Long-term trends and spatial patterns of satellite-retrieved $\mathrm{PM}_{2.5}$ concentrations in South and Southeast Asia from 1999 to 2014. Science of the Total Environment, 615:177-186.

Shang Y, Sun Z, Cao J, et al, 2013. Systematic review of Chinese studies of short-term exposure to air pollution and daily mortality. Environment International, 54(4):100.

Wang J, Xing J, Mathur R, et al., 2017. Historical Trends in $\mathrm{PM}_{2.5}$-Related Premature Mortality during 1990-2010 across the Northern Hemisphere. Environmental Health Perspectives, 125(3):400-408.
Wu Y, Zhang S J, Li M L, et al., 2012. The challenge to $\mathrm{NO}_{x}$ emission control for heavy-duty diesel vehicles in China. Atmospheric Chemistry \& Physics, 12(19):9365-9379.

Xie R, Sabel C E, Lu X, et al., 2016. Long-term trend and spatial pattern of $\mathrm{PM}_{2.5}$, induced premature mortality in China. Environment International, 97:180.

Xu S, Zou B, Shafi S, et al., 2018. A hybrid Grey-Markov/LUR model for PM10 concentration prediction under future urban scenarios. Atmospheric Environment, 187,401-409.

Zheng S, Pozzer A, Cao C X, et al, 2014. Long-term (20012012) fine particulate matter $\left(\mathrm{PM}_{2.5}\right)$ and the impact on human health in Beijing, China. Atmospheric Chemistry \& Physics Discussions, 14(21):5715-5725.

Zhao Y, Zhang J, Nielsen C P, 2012. The effects of recent control policies on trends in emissions of anthropogenic atmospheric pollutants and $\mathrm{CO}_{2}$ in China. Atmospheric Chemistry \& Physics Discussions, 12(9):24985-25036.

Zhang M, Song Y, Cai X, et al, 2008. Economic assessment of the health effects related to particulate matter pollution in 111 Chinese cities by using economic burden of disease analysis. Journal of Environmental Management, 88(4):947-954.

Zou B, Pu Q, Bilal M, et al, 2017. High-Resolution Satellite Mapping of Fine Particulates Based on Geographically Weighted Regression. IEEE Geoscience \& Remote Sensing Letters, 13(4):495-499.

Zou B, Zheng Z, Wan N, et al, 2016. An optimized spatial proximity model for fine particulate matter air pollution exposure assessment in areas of sparse monitoring. International Journal of Geographical Information Science, 30(4):727-747.

Revised Oct 2018 